\title{
Osteomyelitis in Children from Rural Population of Uttar Pradesh
}

\author{
Dinesh Kumar ${ }^{1}$, Priya Mehrishi2* (D), Sameer Singh Faujdar² ${ }^{(D)}$, \\ Satish Kumar² and Amisha Sharma²
}

${ }^{1}$ Department of Microbiology, Krishna Mohan Medical College \& Hospital, Mathura - 281123, Uttar Pradesh, India.

2Department of Microbiology, Maharishi Markandeshwar Medical College and Hospital, Solan - 173 229, Himachal Pradesh, India.

\begin{abstract}
Occurrence of Staphylococcus aureus in children with osteomyelitis. This study was conducted at $\mathrm{K}$. M. M. C. \& Hospital, Mathura (UP). A total of 60 patients with osteomyelitis contributed to this study from October 2017 to October 2019. Patients with known immunodeficiency syndromes were excluded. Specimen collections were meticulously performed to avoid contamination which was accomplished by needle aspiration or surgical sampling. Staphylococcus aureus was recovered in more than half of the cases of osteomyelitis in both infants and children. Amikacin, Clindamycin and Cefazolin were effective in such cases. The distal end of the femur and upper-end tibia were the most common sites of infection where boys were more infected than girls. The haematogenous route was the main cause of the transmission of osteomyelitis in children. Principally Staphylococcus aureus causes the majority of cases of osteomyelitis in children followed by $\mathrm{H}$. influenza, Group B Streptococcus, $P$. aeruginosa, E. coli and Serratia marcescens.
\end{abstract}

Keywords: Osteomyelitis, Staphylococcus aureus, Methicillin Resistant Staphylococcus aureus

(C) The Author(s) 2021. Open Access. This article is distributed under the terms of the Creative Commons Attribution 4.0 International License which permits unrestricted use, sharing, distribution, and reproduction in any medium, provided you give appropriate credit to the original author(s) and the source, provide a link to the Creative Commons license, and indicate if changes were made. 


\section{INTRODUCTION}

Osteomyelitis is an inflammation in bone which is caused by various bacteria ${ }^{1}$. Bacteria can infect bone in three ways that are haematogenous route, direct inoculation through trauma and local invasion ${ }^{2}$. Haematogenous is the main route of causing osteomyelitis in children whereas non-haematogenous route is not common ${ }^{3}$. Staphylococcus aureus is one of the main causes of osteomyelitis, accounting approximately 70-90\% cases. Infections caused by methicillin resistant Staphylococcus aureus (MRSA) are very common globally which is also responsible for causing invasive infections in children which may lead to higher morbidity and mortality ${ }^{4-6}$. Hematogenous-osteomyelitis occurs in the long tubular bone's metaphysis (femur, tibia and humerus). The pathogenesis of hematogenous osteomyelitis differs with different age groups ${ }^{7}$. In children, hematogenous-osteomyelitis begins with bacterial deposition in the metaphysis because of stasis of blood in hair pin like arrangement of blood vessels, deficiency of reticuloendothelial cells at metaphysis, high vascularity at metaphysic and predisposition to trauma ${ }^{8}$. Cellulitis develops in the bone marrow from foci of infection in the metaphysis. Lack of treatment in such infection lead to necrosis of bone and marrow ${ }^{9,10}$. No data is available on osteomyelitis in this part of Uttar Pradesh. Therefore this study was conducted to find out the incidence of osteomyelitis so that better clinical management could be provided to children.

\section{MATERIAL AND METHODS}

All confirmed patients of osteomyelitis willing for the treatment attending $\mathrm{K}$. M. medical college and hospital, participated in this study from October 2017 to October 2019. Eligible participants were all the patients who were previously untreated. A detailed clinical history was taken in all patients. Standard anteroposterior and lateral radiographic views of the elbow were obtained in all cases. Total numbers of 60 patients with osteomyelitis contributed into the study. Antibiotic administration was withheld until the specimen collection was done except in those who were critical and required immediate treatment and intervention. Specimen collections were accomplished by needle aspiration, wound and bone biopsy. All the specimens were cultured on routinely used media ( $5 \%$ Blood and MacConkey agar) and incubated aerobically at $370 \mathrm{C}$ for $24 \mathrm{hrs}$. All isolates were identified by using standard biochemical tests followed by antibiotic susceptibility testing. Detection of MRSA was done by Cefoxitin disc diffusion test by using Clinical \& Laboratory Standards Institute (CLSI) guidelines. Antibiotic discs (HiMedia Laboratories) used were: Ampicillin $(10 \mu \mathrm{g})$, Amoxicillin/Clavulanic acid $(20 / 10 \mu \mathrm{g})$, Cotrimoxazole $(1.25 \mu \mathrm{g} / 23.75 \mu \mathrm{g})$,

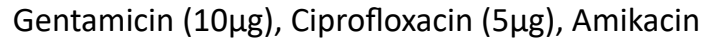
$(30 \mu \mathrm{g})$, Tetracycline $(30 \mu \mathrm{g})$, Cefoxitin $(30 \mu \mathrm{g})$, Cefazolin $(30 \mu \mathrm{g})$, Erythromycin $(5 \mu \mathrm{g})$, Clindamycin $(2 \mu \mathrm{g})$, Linezolid $(30 \mu \mathrm{g})$, Teicoplanin $(30 \mu \mathrm{g})$, Vancomycin Minimum inhibitory concentration $(0.5 \text { to } 32 \mu \mathrm{g} / \mathrm{ml})^{11}$.

\section{RESULTS}

Out of 60 patients, most common organism involved in osteomyelitis is Staphylococcus aureus in forty eight patients (80\%) including MRSA in 4 patients. Other bacterial isolates were $H$. influenzae in three patients, Group B Streptococcus

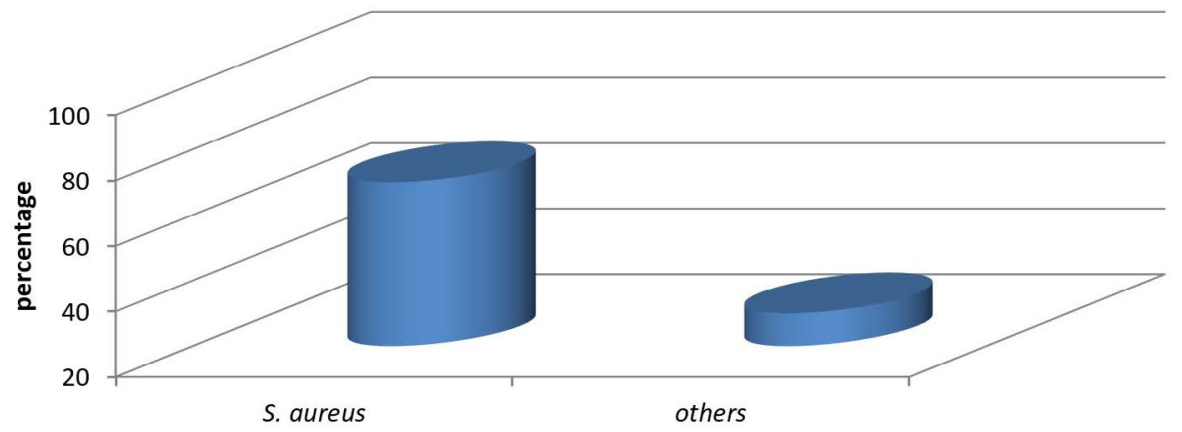

Fig. 1. Distribution of organism causing osteomyelitis 
Table 1. Antibiotic sensitivity pattern of Staphylococcus aureus

\begin{tabular}{lcc}
\hline Antibiotics & $\begin{array}{c}\text { Breakpoints } \\
(\mathrm{mm})\end{array}$ & $\begin{array}{c}\mathrm{S} \\
(\%)\end{array}$ \\
\hline Ampicillin & $\mathrm{S}>=29$ & 70 \\
Amoxicillin/ & $\mathrm{S}>=20$ & 80 \\
Clavulanic acid & & \\
Amikacin & $15-16$ & 90 \\
Gentamycin & $13-14$ & 86 \\
Ciprofloxacin & $16-20$ & 50 \\
Trimethoprim/ & $11-15$ & 85 \\
Sulfamethoxazole & & \\
Clindamycin & $15-20$ & 81 \\
Erythromycin & $14-22$ & 45 \\
Cefazolin & $15-17$ & 92 \\
Linezolid & $\mathrm{S}>=21$ & 100 \\
Vancomycin & $\mathrm{MIC}$ & 100 \\
Teicoplanin & $11-13$ & 100 \\
Tetracycline & $15-18$ & 78 \\
\hline
\end{tabular}

in two patients, Pseudomonas aeruginosa in two patients, E. coli in two patients and Serratia marcescens in one patient and no growth was obtained in two patients (Fig. 01).

All Staphylococcus aureus were $100 \%$ sensitive for Linezolid, Teicoplanin and Vancomycin followed by cefazolin (92\%), Amikacin (90\%), Gentamycin (86\%), and Trimethoprim/ Sulfamethoxazole (85\%) whereas Erythromycin (45\%), Ciprofloxacin (50\%) were less sensitive as described in Table 01.

Maximum patients belonged to age group 6 to $10(37 \%)$ followed by age group 11 to $15(33 \%)$.
Table 2. Age Distribution

\begin{tabular}{lccc}
\hline Age (Years) & Male & Female & Total \\
\hline$\leq 1$ to 5 & 12 & 2 & 14 \\
6 to 10 & 12 & 10 & 22 \\
11 to 15 & 16 & 4 & 20 \\
16 to 18 & 4 & 0 & 4 \\
TOTAL & 44 & 16 & 60 \\
\hline
\end{tabular}

Table 3. Distribution of the Bones Affected

\begin{tabular}{lcc}
\hline $\begin{array}{l}\text { S. } \\
\text { No. }\end{array}$ & $\begin{array}{c}\text { Bone } \\
\text { involved }\end{array}$ & $\begin{array}{c}\text { No. of } \\
\text { Patients (60) }\end{array}$ \\
\hline 01 & Femur & 21 \\
02 & Tibia & 20 \\
03 & Iliac bone & 04 \\
04 & Vertebral & 01 \\
05 & Humerus & 04 \\
06 & Calcaneus & 04 \\
07 & Foot and & 03 \\
& hand bones & 02 \\
08 & Forearm bones & 02 \\
09 & clavicle & 01 \\
\hline
\end{tabular}

Least patient were from age group 16 to 18 (7\%). Among 60 patients, 44 (73\%) patients were male and $16(27 \%)$ were female. Male-to-female ratio $=2.75: 1$ (Table 02).

Predominant involvement of lower limbs was with femur (35\%) and tibia (33\%) whereas other sites combined accounts for $32 \%$ as shown in table 03 and Fig. 02.

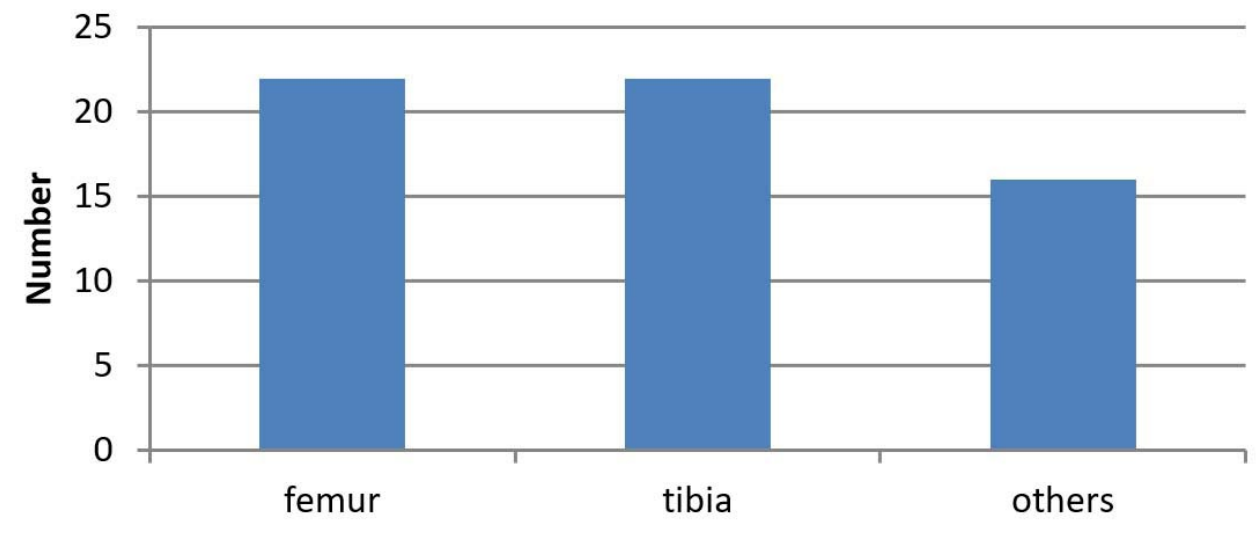

Bone involved

Fig. 2. Distribution of the Bones Affected 


\section{DISCUSSION}

In the current study, most of the osteomyelitis cases were diagnosed with $S$. aureus (80\%). Other studies also documented that $S$. aureus is the most common causative organism in osteomyelitis which accounted within the range of $50 \%$ to $82 \%{ }^{12-14}$. Our study showed $8 \%$ occurrence of MRSA which was lower compared to other studies as described by Senneville et al. (11\%) and Mita et al. $(40 \%)^{15,16}$. In our study linezolid, teicoplanin and vancomycin were showing $100 \%$ sensitivity against $S$. aureus, other studies also revealed the same results ${ }^{17,18}$. In our study, more than $70 \%$ of the patients were found sensitive to cefazolin, amikacin and clindamycin. The isolates were sensitive either to all the three antibiotics in most cases or to one of them in a few cases. Therefore, a policy was framed in our hospital to start the empirical treatment with cefazolin and amikacin for the patients with hematogenous osteomyelitis until the bacterial culture and sensitivity reports comes. If sensitivity was confirmed to these two antibiotics (in case of Staphylococcus aureus, amikacin was discontinued), they were continued for two weeks and the patients would then receive oral clindamycin or were continued with intravenous cefazolin in case child could not take the oral clindamycin for six to eight weeks. Both these cefazolin and amikacin antibiotics are easily available and are of low cost and safe without many serious adverse reactions. In the current study, the male to female ratio is 2.75:1. Most studies $^{19-22}$ invariably demonstrated that majourity of the infection was in male patient. Zaoutis et al. ${ }^{23}$ also found that $62 \%$ of the male patients were most affected. In the current study, $32 \%$ of the infection was seen in femur bone whereas 33\% was seen in tibia bone. Authors from different countries $^{19,20}$ also concluded that most frequently affected sites were femur (34-36\%), tibia (28-33\%) and humerus (14\%).

\section{CONCLUSION}

Haematogenous-osteomyelitis is a serious infection among children, particularly those in pre-school or school. S. aureus was commonest causative organism involved and most of them were sensitive to cefazolin, amikacin and clindamycin. Therefore a policy was framed in our hospital to start empirical treatment with cefazolin and amikacin till bacterial culture and sensitivity reports come. These two antibiotics are affordable, available and safe without many serious adverse reactions.

\section{ACKNOWLEDGMENTS}

The authors acknowledged Department of Microbiology, KMMC \& Hospital, Mathura, U.P., India for providing the research facilities.

\section{CONFLICT OF INTEREST}

The authors declare that there is no conflict of interest.

\section{AUTHORS' CONTRIBUTION}

All authors listed have made a substantial, direct and intellectual contribution to the work, and approved it for publication.

\section{FUNDING}

None.

\section{DATA AVAILABILITY}

All datasets analysed during this study are included in the manuscript.

\section{ETHICS STATEMENT}

This article does not contain any study with human participants or animals performed by any of the authors.

\section{REFERENCES}

1. Nada S Harik, Mark S Smeltzer. Management of acute hematogenous osteomyelitis in children. Expert Rev Anti Infect Ther. 2010;8(2):175-181. doi: 10.1586/ eri.09.130

2. Krogstad P. Osteomyelitis and septic arthritis. In: Feigin RD, Cherry JD, Demmler GJ, Kaplan SL, editors. Textbook of pediatric infectious diseases. $5^{\text {th }}$ ed. Philadelphia, PA: WB Saunders. 2004:713-736.

3. Sattler CA, Mason EO Jr, Kaplan SL. Prospective comparison of risk factors and demographic and clinical characteristics of community acquired, methicillinresistant versus methicillin susceptible Staphylococcus aureus infection in children. Pediatr Infect Dis J. 2002;21(10):910-917. doi: 10.1097/00006454200210000-00005

4. Martinez-Aguilar G, Hammerman WA, Mason EO Jr, Kaplan SL. Clindamycin treatment of invasive infections caused by community-acquired, methicillin resistant and methicillin susceptible Staphylococcus aureus in children. Pediatr Infect Dis J. 2003;22(7):593-598. doi: 10.1097/01.inf.0000073163.37519.ee

5. Martinez-Aguilar G, Avalos-Mishaan A, Hulten 
K, Hammerman W, Mason EO Jr, Kaplan SL. Community-acquired methicillin-resistant and methicillin susceptible Staphylococcus aureus musculoskeletal infections in children. Pediatr Infect Dis J. 2004;23(8):701-706. doi: 10.1097/01. inf.0000133044.79130.2a

6. Kumar D, Bisht D, Faujdar SS. Incidence of Mupirocin Resistance in Staphylococcus Aureus Isolated from Rural Population: A New Emerging Challenge. Int J Cur Res Rev. 2020;12(22):82-85. doi: 10.31782/ IJCRR.2020.12225

7. Frank AL, Marcinak JF, Mangat PD, Schreckenberger PC. Community acquired and clindamycin-susceptible methicillin resistant Staphylococcus aureus in children. Pediatr Infect Dis J. 1999;18(11):993-1000. doi: 10.1097/00006454-199911000-00012

8. Lew DP, Waldvogel FA. Osteomyelitis. Lancet. 2004;364(9431):369-379. doi: 10.1016/S01406736(04)16727-5

9. Krogstad P. Osteomyelitis. In: Feigin RD, Cherry JD, Demmler-Harrison GD, Kaplan SL, editors. Textbook of Pediatric Infectious Diseases. $6^{\text {th }}$ Edition. PA, USA: Saunders Elsevier. 2009:725-742.

10. Green NE, Edwards K. Bone and joint infections in children. Orthop Clin North Am. 1987;18(4):555-576. doi: 10.1016/S0030-5898(20)30352-7

11. Deepa K, Faujdar SS, Azmi W, Mehrishi P, Solanki S. Screening and optimization of staphylokinase from Staphylococcus aureus isolated from nasal swab of healthy students in Himachal Pradesh University, India. Biomed Biotechnol Res J. 2019;3(4):228-232. doi: 10.4103/bbrj.bbrj_128_19

12. Gopi A, Khair SMU, Kottileveetil HT, Harindranath D, Sabapathy V. A clinico-microbiological study of osteomyelitis in a tertiary care hospital in Karnataka. J Evolution Med Dent Sci. 2016;5(1):15-18. doi: 10.14260/jemds/2016/4

13. Chakravarty S, Kataki M, Pradhan U, Yangzom T. "Chronic Osteomyelitis: A Bacteriological Study with Special Reference to Staphylococcus Aureus". Journal of Evidence based Medicine and Healthcare. 2015;2(2):89-96. doi: 10.18410/jebmh/2015/15

14. Moumile K, Merckx J, Glorion C, Pouliquen JC, Berche P, Ferroni A. Bacterial aetiology of acute osteoarticular infections in children. Acta Paediatr. 2005;94:419-422.
15. Senneville E, Melliez H, Beltrand E, et al. Culture of percutaneous bone biopsy specimens for diagnosis of diabetic foot osteomyelitis: concordance with ulcer swab cultures. Clin Infect Dis. 2006;42(1):57-62. doi: 10.1086/498112

16. Wadekar MD, Anuradha K, Venkatesha D. Chronic Osteomyelitis: Aetiology and antibiotic susceptibility pattern. International Journal of recent trends in Science and Technology. 2014;9(3):337-340.

17. Khan RA, Ur Rahman A, Ahmad A, et al. Prevalence and Antibiotic Susceptibility Profile of Methicillin-Resistant Staphylococcus aureus (MRSA) Isolated from Different Clinical Samples in District Peshawar. J Appl Environ Biol Sci. 2014;4(8S):40-46.

18. Fridkin SK, Hagerman JC, Morrison M, et al. Methicillin resistant Staphylococcus aureus disease in three communities. N Eng J Med. 2005;352(14):1436-1444. doi: 10.1056/NEJMoa043252

19. Weichert S, Sharland M, Clarke NM, Faust SN. Acute haematogenous osteomyelitis in children: is there any evidence for how long we should treat? Curr Opin Infect Dis. 2008;21(3):258-262. doi: 10.1097/ QCO.0b013e3283005441

20. DeRonde KJ, Girotto JE, Nicolau DP. Management of Pediatric Acute Hematogenous Osteomyelitis, Part I: Antimicrobial Stewardship Approach and Review of Therapies for Methicillin-Susceptible Staphylococcus aureus, Streptococcus pyogenes, and Kingella kingae. Pharmacotherapy. 2018 Sep;38(9):947-966. doi: 10.1002/phar.2160

21. Arnold SR, Elias D, Buckingham SC, et al. Changing patterns of acute hematogenous osteomyelitis and septic arthritis: emergence of community- associated methicillin-resistant staphylococcus aureus. J Pediatr Orthop. 2006;26(6):703-708. doi: 10.1097/01. bpo.0000242431.91489.b4

22. Malcius D, Barauskas V, Uzkuraite R. Some aspects of long-term results of treatment of acute hematogenous osteomyelitis. Medicina (Kaunas). 2007;43:472-477. doi: 10.3390/medicina43060058

23. Zaoutis T, Localio AR, Leckerman $K$, Saddlemire $S$, Bertoch D, Keren R. Prolonged intravenous therapy versus early transition to oral antimicrobial therapy for acute osteomyelitis in children. Pediatrics. 2009;123(2):636-642. doi: 10.1542/peds.2008-0596 